\title{
Know to change: Gatekeeping and knowledge production
}

\section{Dr Quraysha Bibi Ismail Sooliman, University of Pretoria}

\section{Abstract}

\author{
Journal of Decolonising Disciplines \\ Vol 1 No 22019 \\ eISSN: 2664-340 \\ Issue DOI: \\ https://doi.org/10.35293/jdd.vli2 \\ Article DOI: \\ https://doi.org/10.35293/jdd.vli2.31
}

In order to know how to change, one must be able to acknowledge what one does not know. The curriculum cannot be decolonised if those who manage its very problematic existence do not know, understand, or exhibit an inclination towards what needs to be transformed and what needs to be decolonised. This is because no effort is then made to acquire the necessary skills, approaches or knowledge. Central to knowledge production of relevance is the development of a critical consciousness and a recognition that education is politics, where the decolonisation process is imagined, whilst being cognisant of the purpose of and approach to knowledge. Ideologies, pedagogy and societal visions are then shaped because change and adaptation are necessary for survival and relevance. This paper examines these issues by referencing personal experiences during the \#FMF protests at the University of Pretoria (UP) and the blossoming of intellectualism, which had been aborted in many instances by a corporate university that sought subservience and sycophancy through processes such as gatekeeping. The intellectual response has often been silence, and the questionable claim that 'we are transforming. A robust intellectual project should be in defence of human dignity where academia and the academic work for the greater good of the public makes it relevant.

Keywords: decoloniality, intellectualism, liberalism, humility, academic activism, pedagogy 


\section{Introduction}

When immersing oneself in the diversity of knowledge that exists, a critical engagement with the traditions and ethics of other cultures is an invigorating experience. It is an exciting treasure chest that has until recently remained obscured in westernised South African universities. To demonstrate the benefit of the treasure chest I consider the example of Imam Malik bin Anas (b. 93 AH, d. 179 AH), one of the greatest Islamic scholars of all times. His more than 1300 disciples from all walks of life included rulers, judges, historians, Sufis, poets and students of Islamic texts. The Caliph of the time attended his classes as an ordinary student. Imam Malik showed great respect for knowledge. He considered his own knowledge as a trust and confidently stated that half of knowing is the ability to say 'I don't know'. This reflects an awareness of the importance and value of knowledge, of the responsibility the carrier of knowledge has and of the humility that knowledge should foster. Knowledge should never lead to arrogance, self-enrichment or self-glorification. Serving in an institution of knowledge is equivalent to, or perhaps more meaningful than serving in a political institution. Both positions are positions of trust. Where there is a striving for academic rigour it should be combined with ethics and social relevance. This implies a connection with one's immediate environment and society, since ultimately knowledge is about benefit and relevance, and about building, creating, healing and cohesion. Custodians of knowledge have an ethical duty to use knowledge constructively and 'ethically university-based academic leaders must become public intellectuals who engage the larger public through writing, speaking, or acting' (Parsons 2013: 2). Academics cannot withdraw into the ivory towers and alienate their work and its relevance from the society in which they exist. The ethical duty is understood from the "Greek ethical ideal of adding "character" to a society' (Parsons 2013: 4). This paper considers the ethical quandaries and gatekeeping that academics face in shifting the pedagogy and the individual self towards the transformation and decolonisation of the curriculum and universities in the westernised South African space following the \#FeesMustFall (\#FMF) protests. I adopt a narrative/comparative approach to the gatekeeping of knowledge from a first-person methodology and expand on this experience to consider the different approaches to knowledge production in the Western and Islamic traditions. This process enhances the shift in contemporary pedagogical practice that alienates both 
the academic and the student due to the effect of commodifying knowledge. In a sense that which has occurred is a form of cognitive dissonance between the myth of collegiality and the reality of an intensely competitive individualism that traps the academic in brutal systems of hierarchies.

\section{Ethical pedagogical practice and decolonisation of the self}

Academics and intellectuals face greater challenges and isolation due to the power of corporate culture and corporate mind-sets that have become embedded in the university structures where pedagogy and the curriculum are considered as a technical and instrumental practice. By directing the pedagogical practice in this way, there is a severing of the ethical underpinnings that should guide academics in their understanding of pedagogy and knowledge production, which are both ethical and political acts. The more cynical or 'severed' might argue that my introduction is proselytising; however, an academic process of transformation and decolonisation embodies the pluri-versity where the belief structures of others matter and even add character. Spirituality has contributory value:

Faith ... encourages key notions and core values such as empathy, solidarity, and respect for life as well as compassion ... [Knowledge production should do the same].The encyclical - partly inspired by the liberation theology of Leonardo Boff - listens to the moaning of the poor as much as the moaning of the earth. [Consider this in relation to the analysis on the metric GDP]. It prefers healing to management [This is also how knowledge should function; it should open the potential for creativity and greatness] ... Inter-faith exchange and communication alone will not offer solutions. But they add dimensions to sustainable development we cannot any longer afford to ignore. (Henning Melber 2019)

Knowledge matters, so does spirituality and ethics. British cultural theorist Richard Johnson points out:

Teaching and learning are profoundly political practices. They are political at every moment of the circuit: in the conditions of production (who produces knowledge? for whom?), in the knowledges and knowledge forms themselves 
(knowledge according to what agenda? useful for what?), their publication, circulation, and accessibility, their professional and popular uses, and their impacts on daily life. (Richard Johnson 1997:461)

Knowledge has limitations and presents conundrums. Astute academics are aware of the pitfalls of knowledge production and dissemination, and especially of their own limitations. That is why they can say: 'I don't know-let's find out together. It is never too late to learn.' This approach contradicts Edward Said's (1994:74) conceptualisation of the academic who has resigned himself to the the twin dynamics of accommodation and privatization that inform the culture of professionalism at all levels of education'. This academic conflates professionalism with a means of income, so that the constraints imposed on academic integrity and oppositional intellectualism are not challenged. In this regard, Said maintains that by professionalism he means

... thinking of your work as an intellectual as something you do for a living, between the hours of nine and five with one eye on the clock, and another cocked at what is considered to be proper, professional behavior-not rocking the boat, not straying outside the accepted paradigms or limits, making yourself marketable and above all presentable, hence uncontroversial and unpolitical and "objective". (Edward Said 1994:74)

Scholars who value knowledge recognise this and manifest it in their work. Recognising the limits of one's own knowledge, or the fact that the knowledge one professes to hold dear could be problematic, requires the humility that was so characteristic of Imam Malik, but is largely absent from the westernised university space where academics are chasing rankings, bonuses and claims of 'expertise', so that they can make themselves indispensable. But expertise in what and for whose benefit, and expert according to whom? In instances where academics had engaged in a thoughtful and disciplined social order, increased fragmentation and individualisation in the commodified, westernised, neoliberal university has eroded the potential to critically engage and to be relevant. Academics seek promotion and tenure, and refrain from activism or public dialogue. Instead, the intellectual response has been silence, claiming 'We are transforming. Furthermore, to say 'I don't know' would be to admit to not being the expert, which makes one replaceable. Acknowledging the Other's knowledge and embracing it when in fact it was 
intentionally ignored, is to admit not knowing. Worse still, it could mean that the Other knows what we do not know and is therefore the real expert, which is scary for many. Thus, for many academics, survival is centred on denial of, and resistance to the decolonial/transformational turn. It can then be argued that, as is the case in politics, academic work rarely pursues the 'good life for all', but rather focuses on material benefit for the 'I' as the market has become the mechanism of social control and identity creation.

\section{Education and the instruments of autonomy}

Consider the example of the metric Gross Domestic Product (GDP), created 80 years ago to plan the war economy. Having developed the modern concept of GDP, Simon Kuznets (1962) himself argued against using it to determine the welfare of a nation or advocate for growth where the criteria are not adequately specified. GDP was not created to define progress, but to look at the economic transactions in an economy. It fails to take into account the natural social capital of a society/country. It is a gross indicator giving a false indication of the wealth that is being created. It is strange that the majority of economists/academics have not challenged the fact that wealth is being determined by such an indicator. In this regard, countries like South Africa and other resource-rich countries allow the exploitation of their mineral wealth to increase their GDP, but destroy their environments and sustainability. This does not make sense, since although income is being created, the accompanying destruction is not measured. Achim Steiner, administrator of the United Nations Development Programme (UNDP), states that '[c]limate change, rupturing inequalities, record numbers of people being forced from their homes by conflict and crisis-these are the results of societies that value what they measure instead of measuring what they value' (UNDP Report 2020). A defining aspect of modernity is the differentiated spheres that it has established, where humans are thinking subjects, distinct from the world, using science and human reasoning to exploit the objective world and attain success and progress. This project is forward looking. It is about using what one has now to project even further forward, and there is thus no need to look behind, no need to look at the violence of our actions.

Since this basic fact is known, the metric GDP as an indicator of progress should have been abandoned years ago, considering the potential power of academia and its access to the media. By now there should have been hundreds of critical minds like 
that of the economist Moses Abramovitz who, already in 1959, questioned whether GDP accurately measured a society's overall well-being (Dickinson 2011). However, the dissipation of critical thinking and the prioritisation of rankings and output combined with the nostalgia around Western progress has become so entrenched that academics resign themselves to silence or irrelevance. The fetishism around GDP still prevails despite the creation of alternate indicators such as Bhutan's Gross National Happiness Index (GNH) or the Human Development Index (HDI). This translates as a weakness in education and critical knowledge production, which manifests even in the training and education of journalists. Students do not critically engage with concepts and ideas. Instead of being part of the fourth estate (which consists of individuals from an academic environment) and giving a voice to the voiceless, many journalists simply do not understand numbers or nuances / contexts and history, and blandly report on the news without questioning or some measure of engagement. It should be noted, however, that journalists are also constrained by excessive gatekeeping in the newsrooms.

The exploitative desire for progress uses up what one has now, uses up the inheritance, ignores the past and allows for transgression. To grasp this reality, consider the publication of academic articles such as 'Intelligence and slave exports from Africa', which makes the very racist claim 'that countries with higher IQ levels were more likely to experience lower instances of slave exports from Africa' (Mahopo 2019). What must be questioned is the ethical and academic credibility of journals and institutions that publish research that propose racial stereotypes. Significantly, the paper is still accessible on Munich PersonalRePEcArchive (https:// mpra.ub.unimuenchen.de/93237/1/MPRA_paper_93237.pdf) as an AGDI Working Paper. But it does not end here. The Editorial Board of Aging, Neuropsychology and Cognition published an article about the cognitive skills of 'coloured' women, written by four Stellenbosch University academics. The article drew strong criticism and condemnation from academics and activists 'because of its racist ideological underpinnings, flawed methodology, and its reproduction of harmful stereotypes of "Coloured" women' (Shange 2019). Despite these inconsistencies, the article was published. Why? Yes, while there may have been an academic response that questioned the scientific validity of the content, what needs to be recognised is that those who control the criteria and rankings of academics by publishing them, thus affirming that they are qualified to occupy permanent spaces in academic institutions, continue to accept flawed articles that reinforce the status quo of white supremacy. 
This fact cannot be emphasised strongly enough.

These obfuscations, distortions and disguises clearly demonstrate a neglect of, and disregard for history and a tolerance for transgression, which is achieved through non-critical pedagogy. According to Mabogo More (1996: 127), 'few persons in this country, if any, would argue that academic philosophy has played any major or significant role in setting and arguing for agendas for the unfolding of the South African political situation today'. The reality of irrelevance and significance can be understood through Professor Leonard Praeg's (2018b: 4) referencing of Professor Michael Cloete of UNISA, who asked whether the Philosophical Society of South Africa (PSSA) had any '... moral legitimacy to take us into the future? Given where we find ourselves right now. Given its history of complicity in everything that's gone wrong [for] black people in this country over many, many years.' Praeg (2018b) argues that the question centred on moral legitimacy, '... because until that moment the society had been conducting business as usual, that is, by promoting and sustaining the self-evident supremacy of Western over African philosophy'. Is it not strange that even as late as in 2017, many academic societies and associations had made no or very little effort to heed the call for transformation and decolonisation that had already been stirring for many years?

The above examples refer to an academia, whether in economics, journalism or philosophy, that is complicit in shaping often negative and detrimental perceptions of citizens. From the indoctrination of media agendas to the effect of consumerism, globalisation and material fetishism, what is taught and what is learnt impacts on the development of a society and its people. It affects values, lifestyle choices and ethical stances, since these are ideas that filter down and settle and sediment into the norm. It is worrying that what has not been taught is that progress imbued in Western modernity comes at the expense of inheritance. Is it therefore at all surprising that the peer-reviewed journal Third World Quarterly published 'The case for colonialism', which was seriously flawed? 'Critics generally said that Gilley's pitch for modified colonialism for economically struggling nations who agreed to it completely ignored the historical ills and racism of the system, while some academics criticised the decision to publish the article because 'members of the journal's editorial board said that guest editors declined to consider it as an article and that at least one reviewer had rejected it even as an opinion-style essay' (Flaherty 2018). Nevertheless, the article was published. Gilley espoused an obsession with and belief in Western superiority by admitting that if 'a white supremacist is someone who believes that 
what [V.S.] Naipaul called the "universal civilization currently led by the West" is the cornerstone of global human flourishing', he should be '[c]ount[ed] ... in' as a white supremacist (Flaherty 2018). From an understanding of decoloniality, there is significant criticism of the claim regarding a universal civilisation 'led' by the West, because this implies Western excellence above all else. It also centres the West as the only source of global progress, obscuring all the harm, exploitation, evil, wars and genocide of western colonial and imperial nations that have impoverished and destroyed scores of nations-actions that continue to hamper and restrain those nations' potential to develop. Furthermore, Kwame A. Appiah (2016) maintains that 'there is no such thing as Western civilisation'. Appiah states that the designation West used to describe a 'heritage and object of study', is a modern phenomenon and only really manifested during the 1890s. Significantly, Ramon Grosfoguel (2016) highlights the destructive nature of western civilisation when considered in context. He maintains that from the start of European colonial expansion the world was left with one planetary system which has destroyed all other social/civil/political systems. Thus, the only system that has remained and perpetuated itself is what is known today as Western civilisation. In his article Gilley (2017), a professor of political sciences, argues that 'western colonialism was, as a general rule, both objectively beneficial and subjectively legitimate [my emphasis] in most of the places where it was found ... The countries that embraced their colonial inheritance, by and large, did better than those that spurned it. It is curious that Gilley does not question the impact of colonialism and coloniality or the 'why' of the fact that 'French presidents and ministers are sometimes greeted by protests when they visit former French colonies in Africa' (Jabbar 2013). Nor did he explain that in agreeing to end its colonial stranglehold of African nations France organised its colonies into a system of

... compulsory solidarity, which consisted of obliging the 14 African states to put $65 \%$ of their foreign currency reserves into the French Treasury, plus another 20\% for financial liabilities. This means these 14 African countries only ever have access to $15 \%$ of their own money! (Jabbar 2013)

His article contains many such inconsistencies and deviances, which reflect a skewed and deliberately racist logic, yet The National Association of Scholars chose to republish it after The Third World Quarterly had retracted it, not because of academic incompetency, but because of 'threats' to the journal's editor (Third World Quarterly 
2017). This is an endorsement of misrepresentations in favour of the narrative of Western superiority and 'flourishing' and is the kind of systemic violence that permeates much of the curriculum of the westernised universities. In other words, the horrors of the amputations in colonised Congo, the hangings and destruction by the British in India, 'the suffered poverty, malnutrition, disease, cultural upheaval, economic exploitation, political disadvantage, and systematic programmes aimed at creating a sense of social and racial inferiority' (Alexander 2017) were all legitimate and justified, according to Gilley. Essentially, it was 'objectively beneficial' to be dismembered, destroyed and dehumanised. From this, what is forgotten is that decolonisation starts with the self. It is a political process. The liberation of the ego from the self is a political process and education is a liberating process that equips one with the instruments for one's own autonomy and liberation from thoughts and education systems that shackle the mind.

\section{Gatekeeping and control: A personal experience}

Challenging the gatekeeping and control of knowledge production is also a political act. In 2019, after the attacks in Christchurch, I submitted two articles to The Conversation Africa. The first, '\#ChristChurch: To hate or not to hate?'1 was rejected as it was not 'African' enough, yet The Conversation Indonesia referred it back to The Conversation Africa, requesting the editor to review it as it was newsworthy and The Conversation Africa had published other articles on the attacks. The second article, 'Afrophobia, Islamophobia and white supremacy: Join the dots'2, was submitted after the editor, Caroline Southey, had asked for 'more clarity' on the first. The theoretical grounding and underpinnings of the articles were drawn from my research for my doctorate and highlighted the discrepancies in the representation of white terrorism/ terrorists as opposed to Muslim perpetrators. It also questioned the difference in the language used to identify and describe white perpetrators and non-white/Muslim perpetrators, and the intentional obscuring of the humanity and human essence of black/Muslim victims. Southey chose not to publish the articles stating that what I was proposing would work well for a specialised audience. [I understood that to mean 'a Muslim audience only'.] 'The Conversation exists solely for the purpose

1 https://www.thedailyvox.co.za/christchurch-to-hate-or-not-to-hate/

2 https://www.thedailyvox.co.zalafrophobia-islamophobia-white-supremacy-join-the-dots/ 
of providing access to non-specialist readers. Your summary is clearly written for people well steeped in your area of academic expertise ... Our view remains that the article does not have a link to Africa' (Email communication, 25 March 2019)

The Conversation Africa claims academic rigour and journalistic flair, but academic rigour would mean that the editor would know that Islamophobia and dehumanisation are issues of relevance to African audiences and matter in terms of 'African' content, especially since the majority of the citizens of 19 African countries are Muslim and in approximately eight African countries Muslims account for more than $20 \%$ of the population. Furthermore, the issue of racism is pertinent and a living reality for Africans. Both articles were subsequently published in The Daily Vox, a more student-oriented publication, dispelling the notion of a 'specialised' audience. This highlights the gatekeeping of knowledge that radically challenges stereotypes and distortions. The problem here is that the gatekeepers to academia and the dissemination of academic projects still exercise censorship in favour of a white supremacist agenda. What then occurs is aptly explained by Chomsky when he says that

[t] he smart way to keep people passive and obedient is to strictly limit the spectrum of acceptable opinion but allow very lively debate within that spectrum-even encourage the more critical and dissident views. That gives people the sense that there's free thinking going on, while all the time the presuppositions of the system are being reinforced by the limits put on the range of the debate. (Chomsky 1998: 43)

The ultimate resource that humans have is their creative potential, which needs to be invigorated or nurtured where people can be inspired to challenge stagnant ideologies and ideas to the extent that spaces of academia become spaces wherein the social order is critiqued. In the current global context, the ideas developed should confront neoliberal thought and implementation as 'the power of neoliberalism lies in its saturation of social practices and consciousness, making it difficult to think otherwise' (Lipman 2011: 6). As a result, there is a reluctance to enable critique and motivation for discussions on the language of social investment, protection, justice, equality and accountability, all of which are exacerbated by short-term contracts, downsizing and 'competition between individuals through strategies of individualisation and responsibilisation' (Hofmeyer 2008: 75). For this reason, epistemic decolonisation requires activism and cannot occur in a political vacuum. 


\section{Pedagogy and politics}

The \#FMF protests in South Africa encapsulate the activism in epistemic decolonisation. In his op-ed titled "If classrooms are "free of politics" the right wing will grow', Giroux (2019) maintains that 'it is irresponsible to insist on a politically neutral world where pedagogy is a banal transmission of noncontroversial facts' because this is both a 'flight from reality' and an 'instance of irresponsible pedagogy'. The \#FMF protests highlighted the reality that the politics of the youth as a criterion for political agency and cultural identity was not fully comprehended either within the microcosm of the university or in the broader society. Those interpreting the protests and giving meaning to them did not recognise that it is through the pedagogical force of culture that identities are constructed, citizenship rights are enacted, and possibilities are developed for translating acts of interpretation into forms of intervention' (Giroux 2000: 10). This is what builds an active and dynamic citizenry capable of holding their leaders accountable. The analysis largely focused on growth and economic indicators where the same old arguments were re-hashed, commentators clung 'to the assertion that a thriving free market economy' (with its insidious consumer-based appropriation of notions of freedom and choice) 'provides the greatest good for the greatest number' and where 'the logic of the marketplace blames kids, especially those who are poor, Latino or black, for their lack of character; it also dismantles social services that help them meet their most basic needs' (Giroux 2000: 14). When this logic operates, the fundamental understanding of the collective good is eroded and the resultant actions exacerbate the indignities that the youth continue to suffer. Furthermore, the erosion of the public good is tangible in the constraints on intellectualism where academics are trapped in individualisation which is about the 'setting of individual objectives and assessments, personal increments or bonuses based on individual performance or merit, and individualised career paths' and 'strategies of responsibilisation', which lead to self-exploitation (Hofmeyer 2008: 75).

Praeg (2018a) argues that the securitisation of the universities 'signifies not just intellectual poverty and moral bankruptcy, but also a profound commitment to the depoliticisation of the university at precisely the moment when we are being called upon to interrogate the politics of knowledge production'. Depoliticising academia to maintain the status quo is a political act. It highlights the impact of a system designed to generate passive citizens, uncritical thinkers moulded into 
believing that their freedoms and security are prioritised where 'we are expected to feel safer because of the daily violation of academic and political freedoms-a cognitive dissonance concealed from us by the appeal to the empty signifier "security" (Praeg 2018b: 17). However, it is more than that: Individualisation, responsibilisation and securitisation also involve exclusion, alienation, restraining constitutional freedoms and protections and the closing off of recreational and intellectual spaces accommodated only in a commercial profit-making venture-the commodified university. Gone is the notion and experience of the university as a public good. These are the interrogations championed by the students. The protests reflected the self-organisation and mobilisation of a fragmented public (the body of largely disenfranchised black students) that encountered chaos-the chaos and continued destruction of institutional racism and neo-apartheid, which continued the exploitative legacies of the past. It was a dynamic call for re-calculation, reinvention, and re-modification within an organisation of rigidity so that structures could be changed. The problem is that many academics chose to survive rather than to live. They chose not to participate in the building process, not to share and learn simultaneously. This happens when one becomes individualised to the point of arrogance. There is no longer a desire to learn, but a belief that 'I know it allwhat can you teach me?' This reveals the claim of the expert and the death of the academic. The attitude of the academics resembles the mind-set of power structures in the university.

[S]eparate out from each other the interrogation of historical epistemic injustices and the continued institutionalization of those injustices. Deal with the former but not with the latter. Interrogate how certain knowledges were historically marginalized but not in a way that will focus attention on the institutionalization of those injustices in statues, management practices, pedagogic practices and so on. Limit yourself to the recognition of epistemic injustices but do not connect the dots between recognition and consequences. (Praeg 2018a:2-3).

As a result, the academics could not and largely did not understand or identify with \#FMF. The largely white academia, distanced from the realities of the masses, lay in limbo, trapped through their own neglect (personal choice) and complacency in a system (neoliberal commodified university) many failed to, or were perhaps even 
reluctant to challenge. According to Hofmeyer (2008:75), 'neo-liberalism radically attenuates the individual's capacity to enter the public sphere. This incapacitation leads to the inevitable depoliticisation of intellectual labour through the increasing individualisation of the self, on the one hand, and the rampant privatisation of the public, on the other hand. Considering that epistemic decolonisation requires the politicisation of the intellectual project and that decolonisation and decoloniality are in essence political, it is inevitable that the student protest would address the issue of the neoliberal westernised university in a political context.

Essentially, the protests highlighted the fact that the politics of knowledge and the politics of institutional arrangements that enable the production of knowledge are intricately intertwined. This calls to mind Arendt's notion of the banality of evil and Heslam and Reicher's (2007:616) claim that 'organised evil occurs not when the group obliterates individuality but when "individual and institutional factors meet halfway"', working in unison and towards the same ends. If you do not oppose the system, you coalesce with it. This may seem like a strong statement, but education is a founding pillar of an awakened and active citizenry and any process that stifles the development of citizens and their potential for growth and the ability to live the 'good life' in the name of privileges and benefits for a select few is an evil. This is subordination and a form of slavery. The student protests unwittingly exposed these relationships and the connection between the state and the institutions of knowledge. In all of this it is apparent that the approach to knowledge and thus the approach to decolonisation needs to be ethically considered. There must be a concerted effort to move away from the politics of fear where the white and whitened academia needs to re-imagine a world of humanity, not white privilege. In this re-imagined world, it is okay to say: 'I don't know—come let us learn and question together'.

\section{Conclusion}

There are many approaches to knowledge, decolonisation and transformation. One of these approaches incorporates the shedding of the ego and the I. It is about recognising that 'expertise' can be problematic, especially where it erodes or contributes to the erosion of the greater good to which the academics owe their positions. Without students, there is no need for academics. Thus, the knowledge that is produced and consumed must benefit that society. Considering the history of South Africa and the legacy of the apartheid era, during which whites were privileged and benefitted from 
a racialised structure of domination and indoctrination, it is necessary for white academics to re-imagine the role of education and the production and dissemination of knowledge in the context of decolonisation and transformation. This requires a shift from the politics of fear and privilege to the re-awakening of political agency and activism in academia. It requires admitting that much of what has not been taught, has been hidden or not critiqued, reflects a shortfall in the learning and competence of the academic. This admission does not serve to disqualify the academic where there is an ethical commitment to re-learn and to critically engage. When there is a thirst for knowledge, there is the potential for rebellion which, as Tao Te Ching explains, embodies the reality of the student and the teacher. According to Tao, '[when] the student is ready, the teacher will appear. When the student is truly ready ... the teacher will disappear'. When this happens, we will walk together on the path of the new humanity as a collective South African public-together and side by side. 


\section{References}

Alexander, C. (2017). Colonialism was traumatic even for some British officials who ruled India. https://www.business-standard.com/article/current-affairs/ colonialism-was-traumatic-even-for-some-british-officials-who-ruledindia-117081200153_1.html [Accessed 11 December 2018].

Appiah, K.A. (2016). There is no such thing as western civilisation. https://www. theguardian.com/world/2016/nov/09/western-civilisation-appiah-reith-lecture [Accessed] 11 December 2018].

Chomsky, Noam (1998). The Common Good. Odonian Press.

Dickinson, E. (2011). GDP: A brief history. https:/foreignpolicy.com/2011/01/03/ gdp-a-brief-history/ [Accessed 12 June 2019].

Flaherty, C. (2018). Making 'The case for colonialism' anew. https://www. insidehighered.com/news/2018/06/21/journal-article-was-withdrawn-last-yearamid-intense-debate-republished-national [Accessed 12 June 2019].

Gilley, B. (2017). The case for colonialism. http://www.web.pdx.edu/ gilleyb/2_ The\%20case\%20for\%20colonialism_at2Oct2017.pdf [Accessed 12 June 2019].

Giroux, H.A. (2000). Public pedagogy and the responsibility of intellectuals: Youth, Littleton, and the loss of innocence. JAC 20(1).

Giroux, H.A. (2006). Stormy weather: Katrina and the politics of disposability. Boulder: Paradigm.

Giroux, H.A. (2019). If classrooms are 'free of politics',the right wing will grow. https://truthout.org/articles/if-classrooms-are-free-of-politics-the-right-wingwill-grow/ [Accessed 12 June 2019].

Grosfoguel, R. (2016). Granada Summer School. Critical Muslim Studies Day 1.

Heslam, S. A. \& Reicher, S. (2007). Beyond the banality of evil: Dynamics of an interactionist social psychology of tyranny. Personality and Social Psychology Bulletin.

Hofmeyer, B. (2008). Beyond the ivory tower: The public role of the intellectual today. Phronimon, 9(2).

Jabbar, S. (2013). How France loots its former colonies. https://thisisafrica.me/ france-loots-former-colonies/ [Accessed 10 April 2019].

Johnson, R. (1997). Reinventing cultural studies: Remembering for the best version. From sociology to cultural studies: New perspectives. Ed. Elizabeth Long. Malden, MA: Blackwell. 
Kuznets, S. (1963). How to judge quality. The New Republic. https://static1. squarespace.com/static/5536fbc7e 4 b0d3e $8 \mathrm{a} 9803 \mathrm{aad} / \mathrm{t} / 554 \mathrm{~d} 19 \mathrm{f} 6 \mathrm{e} 4 \mathrm{~b} 000$ 5c69696961/1431116278720/Kuznets_How+to+judge+Quality_1962.pdf [Accessed 12 June 2019]

Lipman, P. (2011). The new political economy of urban education: Neoliberalism, race and the right to the city. New York: Routledge.

Mahopo, Z. (2019). UCT academic resigns over 'racist' research. https://www. timeslive.co.za/news/south-africa/2019-05-16-uct-academic-resigns-over-racistresearch/ [Accessed 13 June 2019].

Melber, H. (2019). Faith as inspiration for politics and development. http://www. developmentresearch.eu/?p=457\#more-457 [Accessed 13 June 2019].

More, M.P. (1996). Complexity, neutrality or advocacy? Philosophy in South Africa, in Theoria 87:124-135 [127], quoted in Ward, J. (2006). Philosophers, their context, and their responsibilities", in Meta 37(5):1-23 [2].

Parsons, J. (2013). The ethical academic: Academics as public intellectuals. https:// files.eric.ed.gov/fulltext/ED539258.pdf [Accessed 12 June 2019].

Praeg, L. (2018a). Postgraduate address. 'Just thinking' - A decolonial perspective on epistemic justice.' Postgraduate Conference, 1 November 2017, Conference Hall, University of Pretoria.

Praeg, L. (2018b). Inaugural address. 'The university as microstate; or: Contemporary modulations of the "ethics of prudent mediocrity"'. Senate Hall, 2 August 2018, University of Pretoria.

Said, E.W. (1994). Representations of the intellectual: The 1993 Reith lectures. New York: Pantheon.

Shange, N. (2019). Study on coloured women's intelligence scientifically flawed, says professor. https://www.timeslive.co.za/news/south-africa/2019-04-25-study-oncoloured-womens-intelligence-scientifically-flawed-says-professor/ [Accessed 13 June 2019].

Third World Quarterly. (2017). The case for colonialism. https://www.tandfonline. com/doi/abs/10.1080/01436597.2017.1369037 [Accessed 12 June 2019].

UNDP Report. (2020). Human Development Report 2020: The next frontier: Human development and the Anthropocene. http:/hdr.undp.org/sites/default/files/ hdr2020.pdf [Accessed 23 December 2020]. 